\title{
The Effectiveness of Ethics Training Strategies: Experiential Learning for the Win
}

\author{
James L. Caldwell ${ }^{1}$, Alisha Y. Ortiz ${ }^{2}$, Erin R. Fluegge ${ }^{1 *}$ and Michael J. Brummett ${ }^{1}$ \\ ${ }^{I}$ Department of Management, Harrison College of Business and Computing, Southeast Missouri State University, Cape \\ Girardeau, MO, USA \\ ${ }^{2}$ Department of Marketing, Harrison College of Business and Computing, Southeast Missouri State University, Cape Girardeau, \\ MO, USA \\ *Correspondence: Erin R. Fluegge, erfluegge@semo.edu
}

\begin{abstract}
Organizations place a great deal of emphasis on ethics, spending significant resources on ethics training initiatives. Research indicates the positive impact that ethical training has on a variety of organizational outcomes. However, in practice, ethics training efforts are often met with resistance and skepticism by employees. This cynicism may be merited and perceived failures in ethics training could be in part a function of the type of ethics training intervention they receive. This study examines the extent to which different types of training interventions impact participants' moral judgment. Evidence suggests that experiential learning is superior to lecture, immersion, behavioral modeling, and role-play. This research contributes to the training and pedagogical literature. It provides evidence suggesting how higher education and industry may better equip students and employees for the ethical challenges they face in today's workplace.
\end{abstract}

General Terms: Education, Training, Ethics, Organizations

Keywords: Ethics training, Behavioral modeling, Experiential learning, Moral judgment

\section{ARTICLE INFORMATION}

Author(s): James L. Caldwell, Alisha Y.Ortiz, Erin R. Fluegge and Michael J. Brummett

Received: 30 Oct, 2020; Accepted: 26 Nov, 2020; Published: 07 Dec,2020 ; e-ISSN: 2347-4696;

Paper Id: BMN-IJBMR-2020-19; rossef member

Citation: doi.org/10.37391/IJBMR.080407

Webpage-link: https://ijbmr.forexjournal.co.in/archive/volume-8/ijbmr-080407.html

\section{INTRODUCTION}

Over the past decade workers have reported increased pressure to violate ethical standards $[1,2]$. From cutting corners on quality, covering up incidents, and deceiving customers [3] to other types of workplace misconduct including abusive behavior, discrimination, and violations of health or safety regulations [2]. The mounting evidence indicates a need for increased ethics in the workplace. In part, this is due to reports that suggest a positive correlation between corporate ethical behavior and the overall strength of culture within an organization through growth in leadership and ideas/values [4]. Companies are responding to this need. Weaver, Trevino and Cochran [5] found that nearly 75 percent of all companies have formal codes of ethics, and over 40 percent have ethics training programs. More recently, the Ethics Resource Center reports 82 percent of organizations have written standards for ethical conduct [1] and over 81 percent of organizations provide training on company standards of ethical workplace conduct [6]. These numbers are important because recent literature has shown evidence that a code of ethics is one of the most vital factors to shape ethical conduct, especially when accompanied by strong ethical training [7].

Having ethical training programs is one thing. Having effective ethical training programs is yet another. Accompanying organizations' increased focus on ethics is a commensurate investment of organizational resources in ethics compliance and training. For example, compliance with the portion of the Sarbanes-Oxley act which specifically deals with accounting fraud was estimated to cost \$2.3 million per firm [8]. In the United States alone, organizations spend billions of dollars annually on employee training and management development [9]. These investments represent an effort to increase productivity, retain key knowledge workers, and create sustainable competitive advantages. However, research suggests that many training and development initiatives are implemented with little evidence-based support for their efficacy and are justified primarily by hope that they will help [9]. More specifically, Gist [10] asserts that despite the considerable amount of money companies invest in training, extant empirical studies on the selection of training design is relatively scarce. This dearth of evidence begs the question: "So, what are these organizations getting for their money?"

Determining which training interventions to include in an ethics training program is challenging, especially when each method presents a trade-off among time, cost, and efficacy. Finding an optimal training intervention for ethics training helps organizations maximize the benefit from their investment. Thus, the purpose of this study is to determine the effectiveness of different ethics training interventions. Accordingly, the objectives of the study are three-fold: 1) to investigate various ethical training intervention strategies, 2) to examine the role of behavioral modeling, and 3) to consider the function of experiential learning, all with respect to their relationship with moral judgment. 


\section{LITERATURE REVIEW}

\subsection{Moral Judgment}

Managerial efforts to create an ethical environment by creating ethical cultures within their organizations are a key component to helping individuals make ethical decisions. Although necessary, environmental factors such as ethical culture alone are not sufficient. Individual factors such as an employee's moral development also play a role. In fact, behavioral ethics research suggests that it is the interaction of the individual and the workplace environmental that will predict ethical decision making in the workplace [11].

Some of the greatest inroads into understanding the process of moral development at the individual level have been made in moral psychology. Kohlberg [12] and Rest [13] assert that people differ in their cognitive moral development and seem to cluster around three general moral schemas when it comes to adhering to a sense of morality. The first, and most basic, involves an appeal to personal interests (personal interest schema) in which case an individual's considerations of whether something is moral focuses on the direct advantages to the actor and on the fairness of simple quid-pro-quo exchanges. It also considers intent and maintenance of relationships. The second schema focuses on the extent to which the decision maintains social laws and norms (maintaining norms schema). The final and most advanced schema (post conventional schema) describes a level of thinking in which considerations focus consensus-producing procedures, due process, rights, and intuitively appealing ideals.

Building on the cognitive moral development theoretical schemas, and in an effort to understand decision making processes, Rest [13] developed a four-component model defining the underlying components of the ethical decisionmaking process. The model starts with the question, "What must we suppose happens psychologically in order for moral behavior to take place?" [14], and the consequent cognitive process is briefly described as follows (Figure 1).

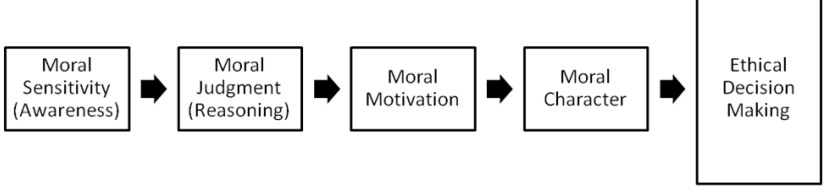

Figure 1: Ethical Decision-Making Process [13].

1. Moral sensitivity (awareness) is defined as interpreting the situation as moral and how our actions affect others.

2. Moral judgment (reasoning) is considered to be the process of judging which action is most justified.

3. Moral motivation describes the prioritization of moral values relative to other values.
4. Moral character includes the concepts of courage, persistence, and overcoming distractions to construct and implement a plan of action.

All four components are viewed as antecedents to moral action, and Rest [14] claims that moral failure can result from deficiency in any of them. The primary focus, however, of this study is the development and measurement of the second step of the process, moral judgment, also known as moral reasoning.

Research suggests that an individual's moral judgment is correlated with a variety of situational, environmental, or contextual factors. Some factors that were found to be related to moral judgment include the organizational culture [15], ethical climate and internal communication [16], existence of organizational codes of ethics [17], training [18], sanctioning systems [19], and leader moral reasoning [20].

In addition to the environmental factors, researchers have noted relationships between individual-level factors and moral judgment. Some individual-level antecedents to moral judgment or moral reasoning include perception factors such as locus of control and risk perception [21], moral awareness [22], hindsight bias [23] and perceived issue importance [24]. Other individual-level factors include cognitive capacities such as pro-social behaviors and professional decision making [25], intelligence and personality type [26], value orientation [27], Machiavellianism [28], spirituality [29], and religion [30]. Studies conducted by Wimalasiri, Pavri, and Jalil [31] and Kracher, Chatterjee, and Lundquist [32] both found a significant relationship between age and moral judgment.

The relationship between gender and moral judgment is tenuous. The results are mixed, with some studies indicating that women make more ethical judgments $[18,30,33]$ and others finding that men do [34]. Moreover, in a meta-analysis of more than 56 studies, Thoma [35] concluded that education was 250 times more powerful than gender in accounting for the variance in moral judgment scores. Hence the relationship with gender is arguably week and inconclusive. However, the evidence for a relationship between moral judgment and education level seems more robust $[32,36]$.

\subsection{Ethics Training Types and Durations}

Types of ethics training interventions in the workplace and classroom may vary. They typically include lectures, discussions, case studies, in-class exercises, role-play, and/or experiential learning. Research on moral education indicates that some methods are more effective than others with respect to moral judgment scores. Bebeau concluded that attending lectures on moral philosophy has no significant impact on participant moral judgment scores based on their performance on the Defining Issues Test-2 (DIT-2). However, engaging in moral problem-solving, discussing case studies and writing arguments that apply criteria for judging the quality of moral arguments has the greatest, albeit modest, impact on moral judgment. 
As for the ideal training duration, Rest and Thoma [36] found that short-term interventions which lasted less than three weeks typically generated no change in moral judgment scores. At the other end of the duration continuum, a longer approach which included a full ethics course ranging between thirteen and twenty-eight weeks, produced no more change than medium duration courses of four to twelve weeks [36]. However, Drake, Griffen, Kirkman, and Swann [37] noted that the temporal differences are not consistently significant when compared to a control group.

Considering the variations in training type and training duration, the optimal training intervention according to the ethical decision-making literature would consist of content that included student-centered moral discourse and last between four and twelve weeks [36]. Given that research indicates that educational interventions can be effective conditions under which individual moral judgment can increase $[25,36,38]$ and the relatively strong explanatory power that education has on moral judgment we provide the following hypothesis:

$\mathrm{H} 1$ : There is a positive relationship between the types of training intervention and moral judgment scores when controlling for participant's education.

\subsection{Behavioral Modeling}

Social cognitive theory [39] provides a theoretical framework for explaining why modeling is an effective form of training. On the importance of vicarious learning, Bandura [40] claimed that learning would become significantly harder and potentially hazardous if people were to learn simply from the effects of their own actions. Human behavior, however, is mainly learned by observation through modeling. As one observes the actions of others, he/she is then able to code this information in their brain to serve as a guide upon how to act in later instances. Bandura [39] suggests a four-component observation learning process as mechanisms through which people learn vicariously (as pictured in Figure 2).

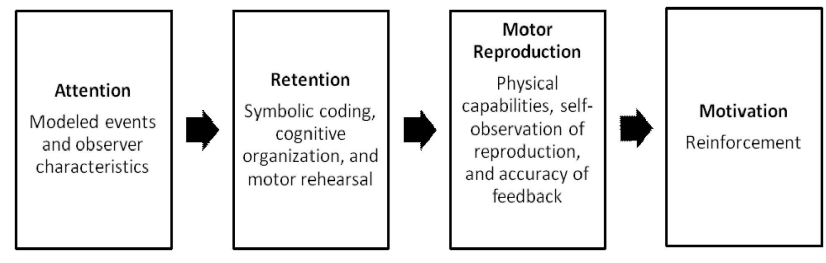

Figure 2: Observation Learning Process.

Bandura [39] also stated that appropriate cues for these processes affect learning. By providing instruction/discussion, role-playing exercises, video-based modeling, and reinforcing employees can potentially cue all four components of the learning process. He further stated that when individuals are exposed to models, they "acquire mainly symbolic representations of the modeled activities which serve as guides for appropriate performances" [40].

Training settings that have utilized behavioral modeling methods have supported this explanation for improved performance [41, 42]. Behavioral modeling has been considered to be the "creation, refinement, and practice of cognitive scripts" as opposed to most other modeling approaches which are typically reproduction based [43]. Thus, training programs that provide models that cue many, if not all of these, processes can be expected to provide more guidance and therefore be more effective than those that cue fewer or none. In a meta-analysis of 70 studies evaluating the effectiveness of management training, Burke and Day [44] concluded that modeling and lecture/discussion with role-play or practice were superior to either lecture or lecture and discussion alone. In a cognitive modeling field experiment, Gist, Schwoerer and Rosen [45] found corroborating evidence. Modeling supported by practice and reinforcement produced significantly higher participant self-efficacy than lecture and practice alone. Latham and Saari, [46] reported compelling evidence of the effectiveness of modeling. They found that it increased supervisor performance with regard to their interpersonal skills. Thus the positive effects of modeling on various outcome variables is encouraging and deserves further evaluation.

Given the evidence provided in favor of modeling as a training method $[10,44,46]$ the educational interventions as effective conditions [36, 38], as well as the theoretical frameworks of Bandura [40] and Rest [13], we suggest that behavioral modeling along with role-play and feedback is likely to have a positive effect on ethics training and offer the following hypothesis:

H2: Participation in ethics training which includes behavioral modeling will be positively related to moral judgment scores.

\subsection{Experiential Learning}

Experiential learning distinguishes itself from behavioral learning processes in that it emphasizes the "central role that experience plays in the learning process" [47]. It proposes that the process and outcome of learning is one and the same [48]. Kolb and Kolb [49] further suggest that learning is the process of relearning, is induced by conflict, is an adaptation to the world, is a result of individuals interacting with their environment, and is a process of creating knowledge.

Kolb's [47] four-stage model is a simple description of the learning cycle which demonstrates how experience is translated through reflection on concepts, which could be guides for active experimentation and the choice of new experiences. Akella [50] describes the four stages which constitute the learning cycle as follows:

1. Concrete experience (CE): provides the basis for the learning process. Lessons are learned by individuals through adaptability and open mindedness rather than a systematic approach to the situation or problem.

2. Reflective observation (RO): students during this stage learn from their experiences and by articulating why and how they occurred. They reflect, observe, and critically examine their experiences from all perspectives. 
3. Abstract conceptualization (AC): relates the observations and reflections made during $\mathrm{RO}$ stage to the theory or subjective concept. Students use logic and ideas as opposed to feelings to understand situations and problems.

4. Active experimentation (AE): during this stage students test the theories to make predictions about reality and then act on those predictions.

These stages follow each other in a cycle; however, the cycle can be entered at any stage. As we consider the implications that experiential learning would have on ethics training, we recognize that the full consequences of an ethical or unethical decision by the participant cannot fully be experienced. However, this study attempts to evoke a similar visceral impact by: (1) establishing ethics criteria for companies as part of the abstract conceptualization (AC) phase, (2) providing opportunity for interacting with and evaluating practitioners in the field according to the criteria as part of the active experimentations (AE) and concrete experience (CE) phases, and (3) reporting their findings as part of the reflective observation (RO) phase. In addition, the successful integration of experiential learning into other traditional classroom topics leads us to believe that it would likewise be effective in cognitive moral development; therefore, we hypothesize that:

H3: Participation in ethics training which includes experiential learning will be positively related to moral judgment scores.

\section{METHODOLOGY}

\subsection{Procedure}

The purpose of this study is to determine the extent to which various training interventions impact measures of employee moral judgment. Thus, participants received varying degrees of ethics training according to which group a participant belonged. Next, a well-established, validated measure of moral cognitive development, the DIT-2 [1999] was administered to four groups of participants.

\subsection{Participants}

Participants for this study consisted of 133 undergraduate and graduate students from two universities located in the Midwest and Northwest regions of the United States, respectively. The average age was 24 years old, the average education level was four years of college, and $40 \%$ of the participants were female.

\subsection{Research Design}

Participants were divided into four different groups: (1) a control group receiving no formal ethics training, (2) a lectureonly group receiving a single-class lecture on moral reasoning and managerial ethical decision making, (3) an immersion/model/role-play group which in addition to the single-class lecture was immersed in a full semester course covering ethics in the workplace, was exposed to a modeling of an ethical decision-making scenario, and then asked to role play, and (4) an experiential group which was immersed in a course covering ethics in the workplace and engaged in an experiential learning activity (Table 1).

\begin{tabular}{|c|c|c|}
\hline Group & Treatment / Intervention & Size \\
\hline 1 & Control (No intervention) & $\mathrm{N}=30$ \\
\hline 2 & $\begin{array}{l}\text { Lecture-Only } \\
\bullet \quad \text { Lecture }\end{array}$ & $\mathrm{N}=22$ \\
\hline 3 & $\begin{array}{l}\text { Immersion/Model/Role-play } \\
\text { - Lecture } \\
\text { - Immersion Course (12 weeks) } \\
\text { - } \quad \text { Modeling/role-play }\end{array}$ & $\mathrm{N}=34$ \\
\hline 4 & $\begin{array}{ll}\text { Experiential } \\
\text { - Lecture } \\
\text { - Immersion Course (4 weeks) } \\
\text { - Experiential Learning (7 weeks) }\end{array}$ & $\mathrm{N}=47$ \\
\hline
\end{tabular}

Table 1: Intervention Group Summary.

One group served as a control group and three additional groups were exposed to varying degrees of ethics training. A total combination of five different interventions was conducted. Interventions included a single lecture, an immersion course in ethics, behavioral modeling demonstration, a role-playing exercise with feedback, and an experiential learning exercise. Specifics about these interventions are described below.

The lecture focused on making ethically defensible managerial decisions in the workplace. Students were provided a brief discussion of applied moral philosophy and managerial decision making. The survey of ethical aptitudes [51] was used as an in-class activity to engage the students and examine ethical predispositions in managerial ethical decision-making processes. In the group receiving only the lecture (Group 2), the lecture was approximately 30 minutes long. In the lecture plus modeling/role-play/feedback (Group 3), the students had received a similar lecture earlier in the semester, thus they were given a shorter lecture as a refresher.

The modeling/role-play component consisted of two parts. First, the researchers, at least one of whom was well known to the participants, modeled an ethical dilemma where one character fired the other. The participants were then given a scenario where a manager was forced to down-size by firing two of six employees. A group discussion was led by the researchers where participants evaluated the merits and unique situations of the six candidates and were encouraged to voice their opinions about who should be fired and why. An assessment was conducted to determine the opinions of the individual participants regarding which of the candidates should be fired. Participants were paired up and role-played the situation by firing each other. Researchers then gave feedback based on what they observed.

The immersion consisted of course work in managerial ethics. Those who belonged to Groups 2 and 3 received twelve weeks of coursework which included lectures, cases, and debates. Those in Group 4 received four weeks of classroom immersion. These durations were both within the optimal times suggested by Rest and Thoma [13]. 
The experiential learning component built upon the four weeks of immersion. An experiential group (Group 4) which was immersed in approximately four weeks of class covering ethics in the workplace was tasked with defining their own criteria for how ethical behaviors are manifested in the workplace. Then, based on those criteria, students spent seven weeks in the field conducting critical assessments of actual organizations. This involved interviews of multiple stakeholders within, as well as, outside the organization. The students then reflected on their findings by submitting a report of their experiences.

Given the strength of the impact that education has on an individual's ability to make moral judgments [25] and that the aim of the current study is to measure the impact that various training interventions have on individual moral judgment, it was important to control for any potential confounds in the model. Accordingly, we introduced education as a control variable in the model.

\subsection{Measures}

Moral judgment was measured by administering the Defining Issues Test (DIT-2) which is a paper-and-pencil measure of moral judgment derived from Kohlberg's theory of moral development [12]. This test was used because of its reliability and validity in hundreds of publications [25]. It consists of five scenarios that present ethical dilemmas. Participants are asked to choose what they would do among two choices. They are then given a series of 12 issues and asked to rate each for its importance in making the decision. Finally, participants are asked to rank the first through fourth most important issues they considered when making the decision. Ten of the issues represent a level of moral reasoning (self-interest, maintaining norms, post-conventional), and two of the issues are reliability tests. The participant is given an N2 score which purports to measure moral development and represents the degree to which a participant activates the personal interest, maintaining norms, and post-conventional schema when approaching moral issues. Higher N2 scores indicate higher levels of moral judgment.

\section{RESULTS}

\subsection{One-way analysis of covariance (ANCOVA)}

A one-way analysis of covariance (ANCOVA) was conducted to determine the impact that ethical training interventions had on moral reasoning. The independent variable, group, included four levels: (1) Control, (2) Lecture-only, (3) Immersion/Model/Role-play/Feedback, and (4) Experiential. The dependent variable was the participant's N2 scores from the DIT-2 and to control for the known effects of education on $\mathrm{N} 2$ scores [25], we set education as a covariate. A preliminary analysis evaluating the homogeneity-of-regression (slopes) assumption indicated that the relationship between the control variable, education, and the dependent variable, N2 score, did not differ significantly as a function of which group to which they belonged, $\mathrm{F}(3,122)=1.90, \mathrm{p}=.132$. Based on these results, we were confident in proceeding with the ANCOVA. The results of the ANCOVA indicated that the relationship between group membership and $\mathrm{N} 2$ score was indeed significant, $\mathrm{F}(3,128)=4.54, \mathrm{p}<.005$. Thus, Hypothesis 1 was supported.

\subsection{Between Group Comparisons}

Based on the results of the ANCOVA, we determined that the type of training makes a difference, but exactly how much is the difference among the various types of training interventions and are those differences statistically significant? Accordingly, Hypotheses 2 and 3 stated that there would be statistically significant gains in $\mathrm{N} 2$ scores for both the behavioral modeling and experiential learning interventions groups. To test the hypotheses, we conducted mean score comparisons through post-hoc analysis to determine the relative change in N2 score based on group affiliation. The results of the analyses lend partial support for Hypothesis 2, such that a positive relationship exists between behavioral modeling and moral judgment scores, but it was not significant. However, Hypothesis 3 was fully supported such that experiential learning and moral judgment were significantly positively related. Results of the analyses are as illustrated in Table 2 and Figure 3.

\begin{tabular}{|l|l|l|l|l|}
\hline & \multicolumn{3}{|l|}{ N2 Score } & Sig \\
\hline Group & Mean & $\begin{array}{l}\Delta \text { from } \\
\text { Baseline }\end{array}$ & S & \\
\hline $\begin{array}{l}\text { 1. No } \\
\text { Intervention/Control } \\
\text { Group (Baseline) }\end{array}$ & 28.28 & - & - & 30 \\
\hline 2. Lecture Only & 24.81 & -3.47 & ns & 23 \\
\hline $\begin{array}{l}\text { 3. } \\
\text { Immersion/Mode1/Role- } \\
\text { play }\end{array}$ & 28.84 & 4.03 & ns & 34 \\
\hline $\begin{array}{l}\text { 4. Experiential } \\
\text { Learning }\end{array}$ & 45.42 & 16.58 & .000 & 47 \\
\hline *Mean differences are significant at $<0.05$ level \\
\hline
\end{tabular}

Table 2: Mean comparisons for N2 scores across different groups.

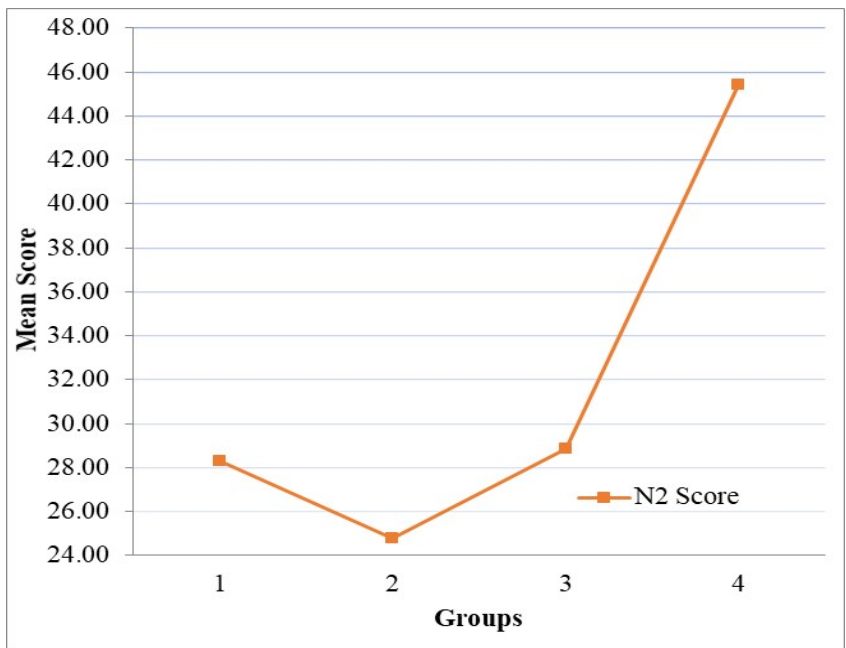

Figure 3: Mean comparisons for N2 scores across different groups. 


\section{DISCUSSION}

\subsection{Overall findings}

Our study was designed to determine the effectiveness of different ethics training interventions with respect to moral judgment as an outcome. Using four different groups (control, lecture-only, behavioral modeling, and experiential learning) allowed us to investigate the effectiveness of each strategy. We looked most closely at the roles of behavioral modeling and experiential learning to determine whether they would have a positive relationship with moral judgment scores. Overall, we found full support for two of the three hypotheses and partial support for the remaining hypothesis.

The broad assertion that being a part of different training interventions would impact a participant's moral judgment score was fully supported (Hypothesis 1). Even though we did not formally hypothesize any findings for Group 2 (which received at least some ethics training in form of a lecture) it is interesting to note the results. Although the lower moral judgment scores for Group 2 might seem counter intuitive, it is not all that surprising given the evidence in the literature which indicates that there is not a statistically significant difference in moral judgment scores as a result of minimal training interventions such as those less than a few weeks. This also falls within the range of the results found in other studies and is not in contradiction to the research in the literature.

The hypothesized results for Group 3 (which were exposed to behavioral modeling) stated that there would be a positive relationship with moral judgment scores. Although we saw a movement in the positive direction, the change was not significant. Therefore, the results only lend partial support for Hypothesis 2. Although the theory is strong to support our hypothesis, and the study design was sound, it is believed that the feedback portion of the intervention was deficient. In theory, participants needed to receive more personalized feedback as opposed to the cursory feedback that actually occurred in the intervention setting.

The experiential learning hypothesis (Hypothesis 3) stated that those who engaged in experiential learning as their primary method of training (Group 4) would have positive and significant gains in their moral judgment scores. Based on the results from the ANCOVA, this hypothesis was fully supported. The experiential learning method was designed to mirror the concrete experience, reflective observation, abstract conceptualization, and active experimentation stages, consistent with Kolb's [47] model of the learning cycle. By establishing ethics criteria, interacting with practitioners, and reporting their findings, participants in the experiential learning condition were encouraged to experience each of the four stages in the cycle.

\subsection{Limitations and Future Directions}

As with all studies this research has its limitations. Although this study was focused on the differences between groups based on the training interventions they received and we were able to conduct a control group in this study, an idea of how much change occurred within each group would also be insightful. Hence in future studies a pre-test, post-test model and a pair-wise comparison within the groups would provide absolute change that occurs within groups which in turn would inform the findings of the relative differences between each group. In addition, the nature of these data are correlational which limits our ability to infer causality. Future longitudinal designed studies of students as they progress through academic programs might be a viable way to determine exactly how much impact ethical interventions have on participants.

Another potential limitation with this research was the use of student samples. The primary concern with this method of convenience sampling is that it limits the investigators' ability to draw generalizable conclusions from the results. In the current research however, our concerns are allayed because the core research questions are investigating pedagogy. Furthermore, the issue of ethics is not isolated to those who are already practicing in industry. Rather, it involves early intervention during the formal educational and training processes which occurs in the college and university setting. In sum, because we are looking at teaching methods and because ethics training needs to begin before they go out into the workplace, we do feel that student samples are warranted.

\subsection{Implications and Conclusion}

In occupations where professionals have a moral obligation to society it is important to explore how those obligations are taught to practitioners and the students who are being socialized into the field. Thus, an important question about implications of this study remains. How can management faculty and others who are charged with training current and future professionals best inculcate these principles? This is especially challenging considering the stark contrast between optimistic training and practical cynicism. In firms where training in general is met with skepticism, the mention of ethics training often receives a collective eye roll from employees. It behooves the organization to consider the most effective and efficient use of its resources when it comes to decisions of ethics training.

Furthermore, empirical results from this study reveal that training interventions that include elements of experiential learning are superior to methods that included lecture, role playing/feedback and behavioral modeling. This stresses the importance of integrating elements of the Kolb [47] model of experiential learning in organizational training initiative. The results of this study will also help managers by offering guidance in the design and execution of effective ethics training programs and maximizing their limited resources.

\section{ACKNOWLEDGMENTS}

A special thanks to Jennifer Roney and Steven Maser for their support in collecting the DIT-2 experiential learning data. We also acknowledge the valuable feedback provided by participants of the American Society for Engineering 
Management 2013 International Conference, the proceedings from which were the foundations for a previous version of this article [52].

\section{REFERENCES}

[1] Ethics Resource Center. (2011). National Business Ethics Survey: Workplace Ethics in Transition. Arlington, VA.

[2] Ethics \& Compliance Initiative. (2020). Global Business Ethics Survey, Pressure in the Workplace: Possible Risk Factors and Those at Risk.

[3] Greengard, S. (1997) 50\% of your employees are lying, cheating \& stealing. Workforce, October, 44-53.

[4] Gupta, N. K., \& Kasana, J. (2017). An Empirical Study on the Effect of Business Ethics on the Company's CSR Practices. International Journal of Business Management \& Research, 7(6), 21-34.

[5] Weaver, G. R., Trevino, L. K., \& Cochran, P. L. (1999). Corporate ethics programs as control systems: Influences of executive commitment and environmental factors. Academy of management Journal, 42, 41-57.

[6] Ethics Resource Center. (2014). National Business Ethics Survey of the U.S. Workplace. Arlington, VA.

[7] Remišová, A., Lašáková, A., \& Kirchmayer, Z. (2019). Influence of Formal Ethics Program Components on Managerial Ethical Behavior. Journal of Business Ethics, 160(1), 151-166.

[8] Freeman, James. (2009) The supreme case against SarbanesOxley. The Wall Street Journal December 15, 2009.

[9] Arthur, W., Bennett, W., Edens, P.S. and Bell, S.T. (2003), Effectiveness of training in organizations: a meta-analysis of design and evaluation features, Journal of Applied Psychology, Vol. 88 No. 2, pp. 234-45.

[10] Gist, M. E. (1989a). The influence of training method on selfefficacy and idea generation among managers. Personnel Psychology, 42, 787-803.

[11] Treviño, L. K. (1986). Ethical decision making in organizations: A person-situation interactionist model. Academy of Management Review, 11, 601-617.

[12] Kohlberg, L. (1984). The psychology of moral development: The nature and validity of moral stages. New York: Harper \& Row.

[13] Rest, J. R. (1986). Moral development: Advances in research and theory. New York: Praeger Publishers.

[14] Rest, J. (1994). Background: Theory and Research, in Moral Development in the Professions, James R. Rest \& Darcia Navaez, Eds. Hillsdale, NJ: Earlbaum.

[15] Razzaque, M. A., \& Hwee, T.P. (2002). Ethics and purchasing dilemma: A Singaporean view. Journal of Business Ethics, 35, 307-326.

[16] Verbeke, W., Uwerkerk, C., \& Peelen, E. (1996). Exploring the contextual and individual factors on ethical decision making of salespeople. Journal of Business Ethics, 15, 1175-1187.

[17] Adams, J. S., Taschian, A., \& Shore, T.H. (2001) Codes of ethics as signals for ethical behavior. Journal of Business Ethics 29, 199-211.

[18] Eynon, G., Hill, N. Y., \& Stevens, K. T. (1997). Factors that influence the moral reasoning abilities of accountants: Implications for universities and the profession. Journal of Business Ethics, 16, 1297-1309.

[19] Tenbrunsel, A. E., \& Messick, D. M. (1999). Sanctioning systems, decision frames, and cooperation. Administrative Science Quarterly, 44, 684-707.

[20] Dukerich, J. M., Waller, M. J., George, E., \& Huber, G. P. (2000). Moral intensity and managerial problem solving. Journal of Business Ethics, 24(1), 29-38.
[21] Cherry, J., Fraedrich, J. (2002). Perceived risk, moral philosophy and marketing ethics. Mediating influences on sales managers' ethical decision making. Journal of Business Research 55, 951962.

[22] Singhapadki, A., Vitell, S. J., \& Kraft, K. L. (1996). Moral intensity and moral decision making of marketing professionals. Journal of Business Research, 36, 245-255.

[23] Sligo, F., Stirton, N. (1998). Does hindsight bias change perceptions of business ethics? Journal of Business Ethics 17, $111-124$

[24] Robin, D. P., Reidenbach, R. E., Forrest, P. J. (1996). The perceived importance of an ethical issue as an influence on the ethical decision making of ad managers. Journal of Business Research 35, 17-28.

[25] Rest, J., Narvaez, D., Thoma, S., \& Bebeau, M. (1999). DIT-2: Devising and testing a revised instrument of moral judgment," Journal of Educational Psychology, 91, 644-659.

[26] Rayburn, J. M., \& Rayburn, L. G. (1996). Relationship between machiavellianism and type A personality and ethical-orientation. Journal of Business Ethics, 15(11), 1209-1219.

[27] Harrington, S.J. (1997). A test of a person - issue contingent model of ethical decision making in organizations. Journal of Business Ethics, 16, 363-375.

[28] Bass, K., Barnett, T., \& Brown, G. (1998). The moral philosophy of sales managers and its influence on ethical decision making. The Journal of Personal Selling and Sales Management, 18, 1-17.

[29] Giacalone, R. A., Jurkiewicz, C. L. (2003). Right from wrong. The influence of spirituality on perceptions of unethical business activities. Journal of Business Ethics 46, 85-97.

[30] Tse, A. C. B., \& Au, A. K. M. (1997). Are New Zealand business students more unethical than non-business students? Journal of Business Ethics, 16, 445-450.

[31] Wimalasiri, J. S., Pavri, F. \& Jalil, A. A. K. (1996). An empirical study of moral reasoning among managers in Singapore. Journal of Business Ethics, 15, 1331-1341.

[32] Kracher, B., Chatterjee, A., Lundquist, A. R. (2002). Factors related to the cognitive moral development of business students and business professionals in India and the United States. Nationality, education, sex and gender. Journal of Business Ethics 35, 255-268.

[33] Reiss, M. C., \& Mitra, K. (1998). The effects of individual difference factors on the acceptability of ethical and unethical workplace behaviors. Journal of Business Ethics, 17, 15811593.

[34] Weeks, W. A., Moore, C. W., McKinney, J. A., \& Longenecker, J. G. (1999). The effects of gender and career stage on ethical judgment. Journal of Business Ethics, 20, 301-313.

[35] Thoma, S. J. (1986). Estimating gender differences in the comprehension and preference of moral issues. Developmental Review, 6, 165-180.

[36] Rest, J. \& Thoma, S. J. (1986). Educational programs and interventions. In J. Rest (ED.), Moral development: Advances in research and theory (pp. 59-88). New York: Prager.

[37] Drake, M., Griffen, P., Kirkman, R., Swann, J. (2005). Engineering Ethical Curricula: Assessment and Comparison of Two Approaches. Journal of Engineering Education, 94 (2), 223-231.

[38] Earley, C. E., \& Kelly, P. T. (2004). A note on ethics educational interventions in an undergraduate auditing course: Is there an 'Enron' Effect'? Issues in Accounting Education, 1, 5371.

[39] Bandura, A. (1997). Self-efficacy: The exercise of control. New York: Freeman.

[40] Bandura, A. (1977). Social learning theory. Englewood Cliffs, NJ: Prentice-Hall, Inc. 
[41] Decker, P. J. (1980). Effects of symbolic coding and rehearsal in behavior-modeling training. Journal of Applied Psychology, 65, 627-634.

[42] Decker, P. J. (1982). The enhancement of behavior modeling training of supervisor skills by the inclusion of retention processes. Personnel Psychology, 35, 323-332.

[43] Lyons, P., \& Bandura, R. P. (2018). Case-based modeling for learning: Socially constructed skill development. Education \& Training, 60(2), 139-154.

[44] Burke, M. J., \& Day, R. R. (1986). A cumulative study of the effectiveness of management training. Journal of Applied Psychology, 71, 232-245.

[45] Gist, M. E., Schwoerer, C. \& Rosen, B. (1989b). Effects of alternative training methods on self-efficacy and performance in computer software training. Journal of Applied Psychology, 74, 884-891.

[46] Latham, G. P., \& Saari, L. M. (1979). The application of social learning theory to training supervisors through behavior modeling. Journal of Applied Psychology, 64, 239-246.

[47] Kolb, D. A. (1984) Experiential learning: Experience as the source of learning and development, Prentice Hall, Englewood Cliffs NJ.
[48] Dewey, J. (1897). My pedagogic creed. The school journal. LIV (3): $77-80$

[49] Kolb, D. A., \& Kolb, A. Y. (2005) Learning styles and learning spaces: Enhancing experiential learning in higher education, Academy of Management Learning and Education, 4(2), 193212.

[50] Akella, D. (2010). Learning together: Kolb's experiential theory and its application. Journal of Management and Organization, 16(1), 100-112.

[51] Brady, F.N. (1990). Ethical Managing: Rules and Results. Macmillan Publishing Company, New York.

[52] Youngblood Ortiz, A. \& Caldwell, J. (2013) Impact of ethics training initiatives: How much is enough? American Society for Engineering Management International Annual Conference Proceedings, USA.

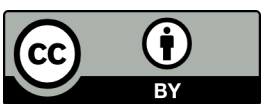

(C) 2020 by the James L. Caldwell, Alisha Y. Ortiz, Erin R. Fluegge* and Michael J. Brummett. Submitted for possible open access publication under the terms and conditions of the Creative Commons Attribution (CC $\quad$ BY) license (http://creativecommons.org/licenses/by/4.0/). 